\title{
On The Development of Photo-Electric Effect
}

\author{
Nishant Kumar Sharma \\ S.B.S P.G. College Rudrapur, Uttrakhand, India \\ Author's mail id: nkphysics11@gmail.com \\ Available online at: www.isroset.org \\ Received: 31/Dec/2019, Accepted: 20/Jan/2020, Online: 28/Feb/2020
}

\begin{abstract}
In This Manuscript We Will Discuss About The Improvement In Einstein's Photo Electric Effect Equation And Then we provide The Equation Of Improved Photo-Electric Effect. Quantum Mechanical Treatment of Modified Photo Electric Effect Equation And Mass of Non intractable particles with varies time lags. Mass of Non intractable Particle in $\mathrm{Gev}-\mathrm{sec} / \mathrm{C}^{2}$ for particle moving at velocity of light at varies time $(\mathrm{t})$, overcome from uncertainty principle and Schrodinger Cat Problem. Non interactive theory of photo electric effect, The Mass of light And Non Intractable particle, Matter Photon Interaction. And finally the conclusion of manuscript.
\end{abstract}

Keywords- Modified photo electric effect equation. Non-Interactive Mechanics, Photo-Electrons.

\section{Article Outline}

1. Introduction

2. Modified Photo electric effect equation.

3. Quantum Mechanical Treatment of Modified Photo Electric Effect Equation And Mass of Non intractable particles with varies time lags.

Mass of Non intractable Particle in Gev $-\mathrm{sec} / \mathrm{C}^{2}$ for particle moving at velocity of Light at varies time (t ).

4. Non interactive theory of photo electric effect.

5. Matter Photon Interaction.

6. Conclusion.

7. References.

\section{INTRODUCTION}

Whenever A Light beam Strike With The Surface Of Metal The Light Photons Transmit The Energy To The Surface Of Metal And Due To This Transmission Of Energy In Form Of Photons Metal's Electrons Emit From Metal's Surface This Incident Called Photo-Electric Effect. Now We Will Describe The Difference Between A Photon And A Non-Intractable Particle, Photons Moves With The Velocity Of Light And Non-Intractable Particles moves 20817.22 m/sec Faster Than Instrument Detected Light. Here we will discuss about the

\section{MODIFIED PHOTO ELECTRIC EFFECT EQUATION}

According to photo electric effect emission of photo electric effect happens instantly as photons strike with the surface of metal. But practically the delay in the emission of photo electrons are $10^{-9} \mathrm{sec}$. So without energy or mass as a meadium photo electrons can't emit from the surface

Of metal so matter is required as a medium for the emission of photo electron this work is done by non intractable particles they emit matter at the surface of metal for the emission of photo electron.

The Relation Of Photo electric effect is

$\frac{1}{2} \mathrm{~m} V^{2}=\mathrm{h}(\mathrm{Vmax}-\mathrm{V} 0)$

Writing The Equation In Form

$\mathrm{h}(\mathrm{Vmax}-\mathrm{V} 0)-\frac{1}{2} \mathrm{~m} V^{2}=0$

According To Non-Interactive Mechanics $\mathrm{N}+\mathrm{M}=0$

$\mathrm{N}+\mathrm{M}=\mathrm{h}(\mathrm{Vmax}-\mathrm{V} 0)-\frac{1}{2} \mathrm{~m} V^{2}$

$\mathrm{N}=\mathrm{h}(\mathrm{V} \max -\mathrm{V} 0)-\frac{1}{2} \mathrm{~m} V^{2}-\mathrm{M}-(1)$ 
This is the Modified Photo electric effect equation.

Now testing the accuracy of above equation

If total energy $\mathrm{E}=\mathrm{hV}$ mav the kinetic energy is $\mathrm{Ek}=\frac{1}{2} \mathrm{~m} V^{2}$ and the rest energy is $E 0=h V 0$

Then

$\mathrm{N}=(\mathrm{E}-\mathrm{E} 0-\mathrm{Ek})-\mathrm{M}$

If $\mathrm{E}=\mathrm{m} c^{2}, E 0=\mathrm{m} 0 \mathrm{c}^{2}, \mathrm{Ek}=(\mathrm{m}-\mathrm{m} 0) \mathrm{c}^{2}$ applying these values in above eq.

$\mathrm{N}=\left(\mathrm{m} c^{2}-\mathrm{m} 0 c^{2}-(m-m 0) c^{2}\right)-M$

$\mathrm{N}=0-\mathrm{M}$

$\mathrm{N}+\mathrm{M}=0$

This is the well known equation of Non interactive Mechanics.

Now we will study the quantum mechanical treatment of Modified photo electric effect equation.

Quantum Mechanical Treatment of Modified Photo Electric Effect Equation And Mass of Non intractable particles with varies time lags

The modified photo electric effect equation is

$$
\mathrm{N}=\mathrm{h}(\mathrm{V} \max -\mathrm{V} 0)-\frac{1}{2} \mathrm{~m} V^{2}-\mathrm{M}
$$

Here the mass $\mathrm{M}$ is the mass of photon $\mathrm{M}=\frac{h V}{c^{2}}$ substituting this value in above equation

$$
\begin{aligned}
& \mathrm{N}=\mathrm{h}(\mathrm{V}-\mathrm{V} 0)-\frac{1}{2} \mathrm{~m} V^{2}-\frac{h V}{C^{2}} \\
& \mathrm{~N}=\mathrm{h} \mathrm{V}\left(C^{2}-1\right) / C^{2}-h V 0-\frac{1}{2} \mathrm{~m} V^{2}
\end{aligned}
$$

For the condition $\mathrm{V}=\mathrm{C}$ and $\mathrm{h} \mathrm{V}=\mathrm{m} C^{2}$ and $h V 0=m 0 C^{2}$

$\mathrm{N}=m C^{2}(0.9719)-m 0 C^{2}-\frac{1}{2} m C^{2}$

$\mathrm{N}=m C^{2}\left(0.9719-1-\frac{1}{2}\right)$

$\mathrm{N}=m C^{2}(-0.5281)$

For $\mathrm{m} C^{2}=h v$

$\mathrm{N}=\operatorname{hv}(-0.5281)$

For $\mathrm{v}=\mathrm{C} /$ lambda and lambda $=1 / \mathrm{t} \quad$ so $\mathrm{v}=\mathrm{ct}$

$\mathrm{N}=\mathrm{h} \mathrm{C} \mathrm{t}(-0.52821)$

Here $\mathrm{h}=6.6 \times 10^{-34} \mathrm{~J}-\mathrm{s}, \mathrm{C}=299792458 \mathrm{~m} / \mathrm{s}$

in Gev / $C^{2}$

$N=18.9874651687(t) \mathrm{Gev} / C^{2}$

Mass of Non intractable Particle in Gev - sec/ $\mathrm{C}^{2}$ for particle moving at velocity of Light at varies time $(t)$

$$
\begin{aligned}
& \text { 1. } \mathrm{t}=10^{-9} \mathrm{sec} . \\
& \mathrm{N}=19 \times 10^{-10} \mathrm{Gev}-\mathrm{sec} / \mathrm{C}^{2} \\
& \mathrm{t}=10^{-10} \mathrm{sec} \\
& \mathrm{N}=19 \times 10^{-10} \mathrm{Gev}-\mathrm{sec} / \mathrm{C}^{2}
\end{aligned}
$$

Point 1 is the value of non intractable particle. These particles moves with the velocity of light and this mass is the source to get non intractable particle and as mentioned in non interactive mechanics this particle can move faster than light . And have the ability of matter emission.

According to quantum mechanical theory a photo electron can be found at two places at the very slight difference of time ( $0.1 \mathrm{sec}$ ) with the same mass value, so this also describe overcome from UNCERTAINTY PRINCIPAL that we could measure position and momentum of a photo particle at a very little or negligible difference of time while the masses are same. This also explain Schrodinger Cat Problem that how a cat dead and alive at a same time and same mass.

\section{NON INTERACTIVE THEORY OF PHOTO ELECTRIC EFFECT}

The Modified Photo Electric Effect Equation is

$$
\begin{aligned}
& \mathrm{N}=\mathrm{h}(\mathrm{V} \max -\mathrm{V} 0)-\frac{1}{2} \mathrm{~m} V^{2}-\mathrm{M} \\
& \text { For } \mathrm{hVmax}=\mathrm{m} C^{2}, h V 0=\mathrm{m} 0 C^{2} \quad \text { and } \mathrm{V}=\mathrm{C} \\
& \mathrm{N}=\mathrm{m} C^{2}-\mathrm{m} 0 C^{2}-\frac{1}{2} \mathrm{~m} C^{2}-M \\
& \text { If } \mathrm{m}=\mathrm{m} 0 /\left(1-V^{2} / C^{2}\right)^{\frac{1}{2}} \text { for } C>>V \\
& \mathrm{~m}=\mathrm{m} 0
\end{aligned}
$$




$$
\begin{aligned}
& \mathrm{N}=\mathrm{m} C^{2}-\mathrm{m} C^{2}-\frac{1}{2} \mathrm{~m} C^{2}-M \\
& \mathrm{~N}=\mathrm{m} C^{2}(1-1-1 / 2)-M \\
& \mathrm{~N}=\mathrm{m} C^{2}(-0.5)-M \\
& \mathrm{M}=\mathrm{m} \\
& \mathrm{N}=\mathrm{m}\left(C^{2}(-0.5)-1\right)
\end{aligned}
$$

The Mass of light And Non Intractable particle.

For C light $=\mathbf{2 9 9 7 9 2 4 5 8} \mathbf{~ m} / \mathbf{s e c}$

$\mathrm{N}=\mathrm{m}(-18.7640762647) \mathrm{m} / \mathrm{sec}$

Here $\mathrm{m}=\frac{4 \pi V}{3 h^{3}} \cdot \frac{1}{4} \sqrt{\frac{8 m^{3} \pi}{\beta^{3}}} \cdot e^{\frac{\beta p^{2}}{2 m}}$

Substituting this value in above equation.

$\mathrm{N}=(-18.7640762647) \frac{4 \pi V}{3 h^{3}} \cdot \frac{1}{4} \sqrt{\frac{8 m^{3} \pi}{\beta^{3}}} \cdot e^{\frac{\beta p^{2}}{2 m}}$

Here ' - ve' sign denote the disintegration of matter.

For $\mathrm{N}=-\mathrm{M}$

$M=(18.7640762647) \frac{4 \pi V}{3 h^{3}} \cdot \frac{1}{4} \sqrt{\frac{8 m^{3} \pi}{\beta^{3}}} \cdot e^{\frac{\beta p^{2}}{2 m}}$

This is the new mass formed during the photo electric effect for light particles.

Now-

$\mathrm{N}=\mathrm{m}(-18.7640762647) \mathrm{m} / \mathrm{sec}$

Dividing it by $299792458 \mathrm{~m} / \mathrm{sec}$

$\mathrm{N}=\mathrm{m}(-0.0000000626)$

As we predicted $\mathrm{N}=19 \times 10^{-10} \mathrm{Gev}-\mathrm{sec} / \mathrm{C}^{2}$

As $\mathrm{N}=-\mathrm{m}$

$\mathrm{m}=-19 \times 10^{-10} \mathrm{Gev}-\mathrm{sec} / \mathrm{C}^{2}$

Substituting this in equation

$\mathrm{N}=\mathrm{m}(-0.0000000626)$

$\mathrm{N}=\left(-19 \times 10^{-10}\right) \cdot(-0.0000000626) \mathrm{Gev}-\mathrm{sec} / \mathrm{C}^{2}$

$\mathrm{N}=-13.4160753862 \mathrm{Gev}-\mathrm{sec} / \mathrm{C}^{2}$

As $\mathrm{N}=-\mathrm{M}$

$\mathrm{M}=13.4160753862 \mathrm{Gev}-\mathrm{sec} / \mathrm{C}^{2}$

So Mass of light $=13.4160753862 \mathrm{Gev}-\mathrm{sec} / \mathrm{C}^{2}$

For C non intractable $=\mathbf{2 9 9 8 1 3 2 7 5 . 2 2} \mathbf{~ m} / \mathbf{s e c}$

$\mathrm{N}=\mathrm{m}(-18.76543232) \mathrm{m} / \mathrm{sec}$

Here $\mathrm{m}=\frac{4 \pi V}{3 h^{3}} \cdot \frac{1}{4} \sqrt{\frac{8 m^{3} \pi}{\beta^{3}}} \cdot e^{\frac{\beta p^{2}}{2 m}}$

Substituting this value in above equation.

$\mathrm{N}=(-18.76543232) \cdot \frac{4 \pi V}{3 h^{3}} \cdot \frac{1}{4} \sqrt{\frac{8 m^{3} \pi}{\beta^{3}}} \cdot e^{\frac{\beta p^{2}}{2 m}}$

Here '- ve' sign denote the disintegration of matter.

For $\mathrm{N}=-\mathrm{M}$

$\mathrm{M}=(\mathbf{1 8 . 7 6 5 4 3 2 3 2}) \frac{4 \pi V}{3 h^{3}} \cdot \frac{1}{4} \sqrt{\frac{8 m^{3} \pi}{\beta^{3}}} \cdot e^{\frac{\beta p^{2}}{2 m}}$

This is the new mass formed during the photo electric effect for Non intractable particles Now-

$\mathrm{N}=\mathrm{m}(-18.76543232) \mathrm{m} / \mathrm{sec}$

Dividing this by $299813275.22 \mathrm{~m} / \mathrm{sec}$

$\mathrm{N}=\mathrm{m}(-0.0000000626)$

As we predicted $\mathrm{N}=19 \times 10^{-10} \mathrm{Gev}-\mathrm{sec} / \mathrm{C}^{2}$

As $\mathrm{N}=-\mathrm{m}$

$\mathrm{m}=-19 \times 10^{-10} \mathrm{Gev}-\mathrm{sec} / \mathrm{C}^{2}$

Substituting this in equation

$\mathrm{N}=\mathrm{m}(-0.0000000626)$

$\mathrm{N}=\left(-19 \times 10^{-10}\right) \cdot(-0.0000000626) \mathrm{Gev}-\mathrm{sec} / \mathrm{C}^{2}$ 
$\mathrm{N}=-13.4160753862 \mathrm{Gev}-\mathrm{sec} / \mathrm{C}^{2}$

As $\mathrm{N}=-\mathrm{M}$

$\mathrm{M}=13.4160753862 \mathrm{Gev}-\mathrm{sec} / \mathrm{C}^{2}$

So Mass of non intractable particle $=13.4160753862 \mathrm{Gev}-\mathrm{sec} / \mathrm{C}^{2}$

So According to non interactive theory of photo electric effect the mass value for light and non intractable particle extend to new limits. Or new Mass formed during the photo electric effect.

So the mass of light and non intractable particle both are approximately same with very little difference. But The velocities are different non intractable particle is $20817.22 \mathrm{~m} / \mathrm{sec}$ faster than the velocity of light.

\section{MATTER PHOTON INTERACTION}

The Modified Photo electric effect equation is

$$
\begin{aligned}
& \qquad \mathrm{N}=\mathrm{h}(\mathrm{V} \max -\mathrm{V} 0)-\frac{1}{2} \mathrm{~m} V^{2}-\mathrm{M} \\
& \text { Now denoting } \mathrm{h}(\mathrm{V} \max -\mathrm{V} 0)-\frac{1}{2} \mathrm{~m} V^{2}=N e \\
& \text { So } \mathrm{N}=\mathrm{Ne}-\mathrm{M} \\
& \text { If the value of } \mathrm{M} \text { is '-ve' then } \\
& \quad \mathrm{N}=\mathrm{Ne}+\mathrm{M}
\end{aligned}
$$

So for The condition when matter disintegrate ( $M$ is '-ve') during the process of photo electric effect the result is more matter and photo particle available for the process of photo electric effect. So The reaction rate is high during the disintegration of matter in photo electric effect

Here $\mathrm{hv}>\mathrm{h} \mathrm{V0}+\frac{1}{2} \mathrm{~m} V^{2}$

If the value of $\mathrm{M}$ is ' + ve' Then

$$
\mathrm{N}=\mathrm{Ne}-\mathrm{M}
$$

Here $\mathrm{hv}<<\mathrm{h} \mathrm{VO}+\frac{1}{2} \mathrm{~m} V^{2}$

So for The condition when matter doesn't disintegrate ( $\mathrm{M}$ is '+ve' ) during the process of photo electric effect the result is less matter and photo particle available for the process of photo electric effect. So The reaction rate is low for matter doesn't disintegrate during photo electric effect.

So the value of Matter $\mathrm{M}$ decide the reaction rate of matter photon.

\section{CONCLUSION}

In Above Manuscript We Discussed About Einstein's Photo-electric Effect And Then we improved the Equation in form of $\mathrm{N}=\quad-\mathrm{M}+\mathrm{h}(\mathrm{V} \max -\mathrm{V} 0)-\frac{1}{2} \mathrm{~m} V^{2}$.This relation satisfies non interactive mechanics equation $\mathrm{N}+\mathrm{M}=0$

After this we treated this modified equation by quantum mechanics and get the formula for the mass of non intractable particle and then we get the positive mass value of non intractable particle at $\mathrm{t}=10^{-9} \mathrm{sec}, t=10^{-10} \mathrm{sec}$ and both are same $19 \times 10^{-10} \mathrm{Gev}-\mathrm{sec} / \mathrm{C}^{2}$. This describe the many quantum mechanical phenomena such as uncertainty problem Schrodinger cat problem.

Then we treated the modified equation by non interactive mechanics and get the mass of light and non intractable particle and both are same so they are only identify by the velocities and momentum and their non interactive masses.

The matter photon interaction and the possibility of equation discussed at last, that the value of disintegrated matter describe the rate of matter photon interaction.

\section{REFERENCES}

[1] Nishant Kumar Sharma, Non-Interactive Mechanics, Journal of Nuclear And Particle Physics, Vol.9 No.1, 2019, pp. 18-41. doi:10.5923/j.jnpp.201909901.03.

[2] Tayal D. C. , "Nuclear Physics", Himalaya Publishing House, 2017

[3] Upadhyaya J. C. , "Classical Mechanics", Himalaya Publishing House ,2016.

[4] "This Research Did Not Receive Any Specific Grant From Funding agencies In Public, Commercial ,or Not-For-Profit Sectors."

\section{AUTHORS PROFILE}

Mr. Nishant Kumar Sharma is B.sc,, M.sc . in. Physical Science from Kumaun University, Nainital in 2015, 2017. He is currently working as Independent Researcher and Published Two Articles in international journals which unifies Classical, Relativistic and quantum mechanics, the papers Are Non Interactive mechanics, Law of gravitation for Non Intractable Particles. Article Law of gravitation for Non Intractable Particles is published in ISROSET Journal IJSRPAS. 